\title{
Multilevel Percutaneous Vertebroplasty (More than Three Levels) in the Management of Osteoporotic Fractures
}

\author{
Ihab Zidan, M.D., Ahmed Abdelaziz Fayed, M.D., Amr Elwany, M.D. \\ Department of Neurosurgery, Faculty of medicine, Alexandria University, Alexandria, Egypt
}

Objective : Percutaneous vertebroplasty (PV) is a minimally invasive procedure designed to treat various spinal pathologies. The maximum number of levels to be injected at one setting is still debatable. This study was done to evaluate the usefulness and safety of multilevel PV (more than three vertebrae) in management of osteoporotic fractures.

Methods : This prospective study was carried out on consecutive 40 patients with osteoporotic fractures who had been operated for multilevel PV (more than three levels). There were 28 females and 12 males and their ages ranged from 60 to 85 years with mean age of 72.5 years. We had injected 194 vertebrae in those 40 patients (four levels in 16 patients, five levels in 14 patients, and six levels in 10 patients). Visual analogue scale (VAS) was used for pain intensity measurement and plain X-ray films and computed tomography scan were used for radiological assessment. The mean follow-up period was 21.7 months (range, 12-40).

Results : Asymptomatic bone cement leakage has occurred in 12 patients (30\%) in the present study. Symptomatic pulmonary embolism was observed in one patient. Significant improvement of pain was recorded immediate postoperative in 36 patients (90\%).

Conclusion : Multilevel PV for the treatment of osteoporotic fractures is a safe and successful procedure that can significantly reduce pain and improve patient's condition without a significant morbidity. It is considered a cost effective procedure allowing a rapid restoration of patient mobility.

Key Words : Percutaneous vertebroplasty · Bone cement · Osteoporotic fractures · Polymethyl methacrylate.

\section{INTRODUCTION}

Percutaneous vertebroplasty (PV) is a minimally invasive procedure in which bone cement is injected into the vertebral body. This technique was first performed by Deramond and Galibert in 1987 for the treatment of vertebral hemangiomas ${ }^{20}$. Since that time, PV gains a worldwide popularity and was used in the management of various spinal pathologies as metastasis and osteoporosis. With the increase of the aging population all over the world, osteoporotic fractures become very common in the daily practice ${ }^{16)}$.

$\mathrm{PV}$ is very efficient technique in reducing pain associated with osteoporotic fractures resulting from the local chemical, vascular and thermal analgesic effect of polymethylmethacrylate (PMMA) on nerve endings of surrounding tissues. In addition, it allows immediate stabilization of the fractured bone by the bone cement ${ }^{913,34)}$. Patients with osteoporotic fractures can face a single or more commonly a multilevel affection. Still

- Received : September 18, 2017 •Revised : September 28, 2017 •Accepted : November 20, 2017

- Address for reprints : Ihab Zidan, M.D.

Department of Neurosurgery, Faculty of medicine, Alexandria University, 15 Champollion Street, El-Khartoum Square, Alexandria, Egypt

Tel : +20-1223558137, Fax : +20-34873076, E-mail : zidanihab@yahoo.fr

This is an Open Access article distributed under the terms of the Creative Commons Attribution Non-Commercial License (http://creativecommons.org/licenses/by-nc/4.0) which permits unrestricted non-commercial use, distribution, and reproduction in any medium, provided the original work is properly cited. 
no agreement about the maximum levels to be injected at one $\operatorname{session}^{16)}$.

\section{MATERIALS AND METHODS}

Between June 2010 and May 2015, all patients who underwent multilevel PV (more than three levels) for osteoporotic compression fractures were collected. There were 28 females and 12 males and their ages ranged from 60 to 85 years with mean age of 72.5 years. All patients were subjected to detailed history taking and neurologic examination. As regards the clinical presentation, all patients had presented with back pain before surgery. All patients had preoperative plain X-ray, computed tomography (CT) and magnetic resonance imaging (MRI) examination. Vertebral collapse and MRI signal changes in the short tau inversion recovery (STIR) sequence were used to determine the number of vertebrae requiring vertebroplasty in our patients. Bone marrow oedema detected by STIR sequence of MRI was used to differentiate between healed and non-healed fractures. Patients with osteoporotic fractures were followed side by side by internal medicine doctors for treatment of osteoporosis. Calcitonin-salmon (Miacalcin) nasal spray, calcium and vitamin D supplements, bisphosphonates as well as wellbalanced diet, regular exercise program, smoking cessation were provided for all osteoporotic patients. Physical therapy, back braces, muscle relaxants and analgesics were used to control pain.

\section{Inclusion criteria}

Patients with painful multilevel (more than three levels) osteoporotic vertebral compression fractures without radiological evidence of neural compression and who showed no response after medical treatment or progression of vertebral fracture. Patients with less than three osteoporotic vertebral compression fractures but where prophylactic vertebroplasty was performed for borderline adjacent vertebrae which showed bone marrow oedema in the STIR sequence of MRI. Patients with recent and old symptomatic osteoporotic fractures were included in the study.

\section{Exclusion criteria}

Patients with osteoporotic fractures requiring injection in three levels or less and fractures due to neoplastic pathology.
Patients with coagulation disorders or any local or systemic infection. Destruction of the posterior vertebral cortex as well as decreased vertebral height were not considered exclusion criteria.

\section{Surgical technique}

PV using the PMMA was performed under local anesthesia with light sedation in all our patients. Patients were placed in prone position with abdominal and thoracic support to allow adequate ventilation. A completely sterile technique was used. The transpedicular approach was performed for all our thoracic and lumbar vertebral fractures. The transpedicular needle was introduced in the anterior third of the vertebral body. The cement mixture was then injected gradually through the needle with careful fluoroscopic control in both anteroposterior and lateral views. Adequate consistency of bone cement was required before injection to decrease the incidence of the leakage. Cement leakage was detected during injection with immediate cessation when it happened and then restarted again after one minute. A unilateral transpedicular injection was used in most of our patients. In the cases for whom unilateral injection was not satisfactory or for whom there was a need for both pedicles to be stabilized, a bipedicular approach was used.

We had injected 194 vertebrae in those 40 patients (four levels in 16 patients, five levels in 14 patients, and six levels in 10 patients) (Figs. 1 and 2). Vertebroplasty included 140 lumbar vertebrae and 54 dorsal vertebrae. Vertebroplasty was performed for 124 (64\%) fractured vertebrae while prophylactic
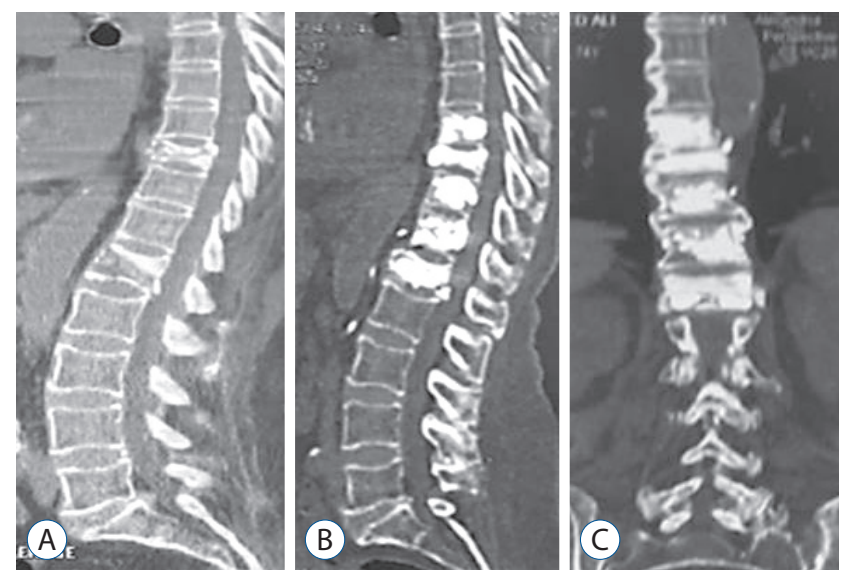

Fig. 1. CT scan (sagittal view) showing a D10 and L1 osteoporotic fractures in a 73 years old female patient (A). Postoperative CT scan follow-up after one year (sagittal and coronal cuts) showing multilevel percutaneous vertebroplasty from $D 9$ to $L 1$ with good restoration of the vertebral heights after vertebroplasty (B and C). CT: computed tomography. 


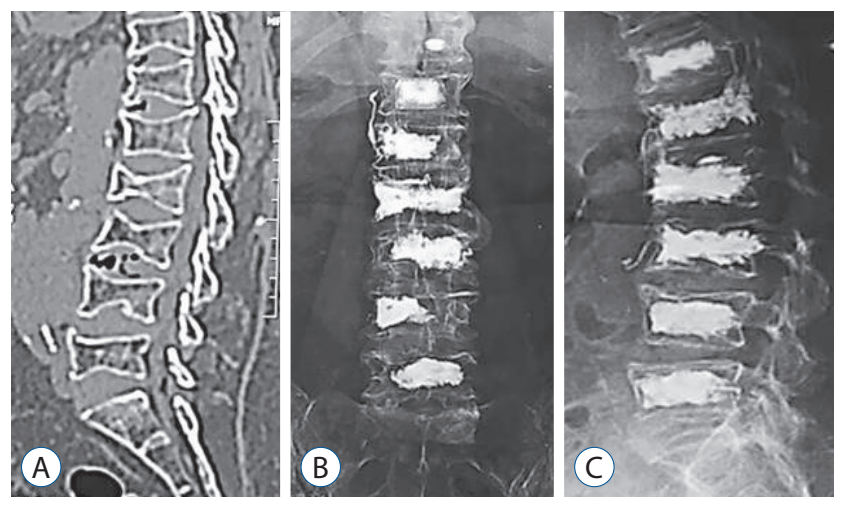

Fig. 2. CT scan (sagittal view) showing multiple dorsolumbar osteoporotic fractures in a 77 years old female patient (A). Postoperative plain $\mathrm{x}$-ray followup (axial and lateral views) showing multiple level vertebroplasty from D12 to L5 (B and C). CT : computed tomography.

injection was done in 70 borderline vertebrae (36\%). Unilateral transpedicular injection was done in 124 vertebrae.

\section{Postoperative care and follow up}

Postoperatively, all patients were neurologically examined with assessment of motor power. Visual analogue scale (VAS) was used for pain intensity measurement and plain X-ray films (AP and lateral views) and CT scan were used for radiological assessment in all our patients. Patients were evaluated regularly immediate post vertebroplasty and then every 6 months both clinically and radiologically. Spinal MRI was performed if any neurological deficit appears or if the back pain increases in severity during the follow up. The mean follow-up period was 21.7 months (range, 12-40) including both clinical and radiological examinations.

\section{Statistical analysis of the data}

Data were analyzed using IBM SPSS software package version 20.0 (IBM SPSS Inc., Chicago, IL, USA). Qualitative data were described using number and percent. Quantitative data were described using range, mean, standard deviation and median. For ordinal data to compare between the different periods, Wilcoxon signed ranks test was applied. Significance of the obtained results was judged at the $5 \%$ level.

\section{RESULTS}

PV was performed for osteoporotic vertebral compression fractures in 54 dorsal and 140 lumbar vertebrae in the present
Table 1. Distribution of studied patients according to demographic data, BMD and level injected

\begin{tabular}{|c|c|}
\hline & Value \\
\hline \multicolumn{2}{|l|}{ Age (years) } \\
\hline $60-70$ & $24(60)$ \\
\hline $71-80$ & $12(30)$ \\
\hline$>80$ & $4(10)$ \\
\hline Range & 60 to 85 \\
\hline Mean \pm SD & $72.5 \pm 7.45$ \\
\hline \multicolumn{2}{|l|}{ Gender } \\
\hline Female & $28(70)$ \\
\hline Male & $12(30)$ \\
\hline \multicolumn{2}{|l|}{ BMD } \\
\hline Range & -4.20 to -1.80 \\
\hline Mean \pm SD & $-3.03 \pm 0.85$ \\
\hline Mean time of symptoms (weeks) & $4.6(1-11)$ \\
\hline \multicolumn{2}{|l|}{ Type of level injected } \\
\hline Lumbar & $140(72)$ \\
\hline Dorsal & $54(28)$ \\
\hline \multicolumn{2}{|l|}{ Number of levels injected } \\
\hline 4 levels & $16(40)$ \\
\hline 5 levels & $14(35)$ \\
\hline 6 levels & $10(25)$ \\
\hline \multicolumn{2}{|l|}{ Frequency of level injected } \\
\hline D7 & 2 \\
\hline D8 & 2 \\
\hline D9 & 2 \\
\hline D10 & 4 \\
\hline D11 & 10 \\
\hline D12 & 34 \\
\hline L1 & 34 \\
\hline L2 & 32 \\
\hline L3 & 26 \\
\hline L4 & 26 \\
\hline L5 & 22 \\
\hline
\end{tabular}

Values are presented as number (\%) unless otherwise indicated. BMD : bone mineral density, SD : standard deviation

study. The most common injected levels were D12 and L1 vertebrae injected in 34 patients each followed by L2 level injected in 32 patients (Table 1). The least levels injected were D7, D8, and $\mathrm{D} 9$ found in two patients each. The average amount of bone cement injected was $5.6 \mathrm{~mL}$ in the lumbar spine and $4.3 \mathrm{~mL}$ for the dorsal spine. MRI was performed in one patient in whom 

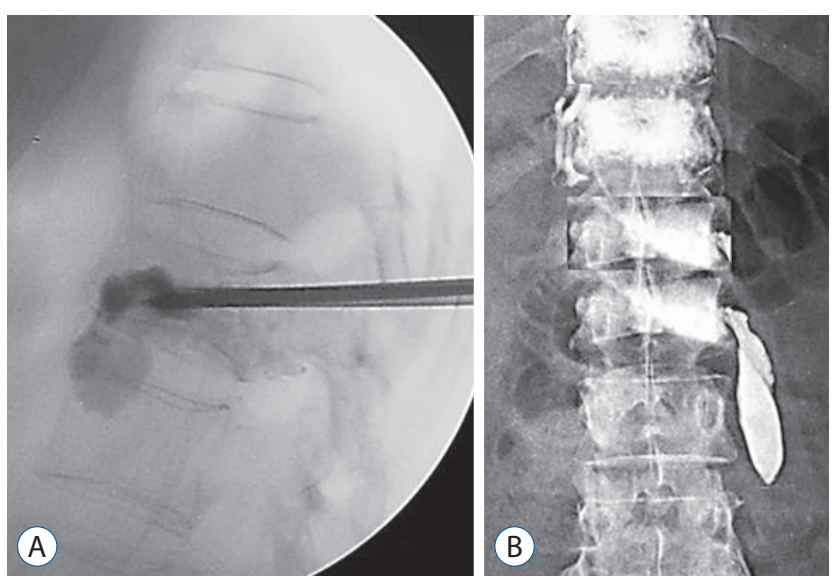

Fig. 3. Examples of cement leakage after vertebroplasty. A : Leakage in the disc space. B: Paravertebral leakage.

back pain had increased in intensity after vertebroplasty without recent CT explanation. His MRI was insignificant and good response to analgesic was observed later on.

\section{Bone cement leakage}

Asymptomatic bone cement leakage has occurred in $12 \mathrm{pa}-$ tients (30\%); leakage in the disc space in six patients and paravertebral leakage in the other six patients (Fig. 3). All those patients were doing fine and no further management was required. Symptomatic pulmonary embolism was observed in one patient without an evident cement leakage. This patient has presented with dyspnea postoperatively and required intensive care unit (ICU) admission and received anticoagulant with satisfactory recovery. None of the patients developed discitis or epidural leakage.

\section{Back pain}

The VAS was used to assess the degree of back pain improvement after PV. The VAS was assessed immediate postoperative and then every six months. The preoperative low back pain VAS mean value was 8.25. Immediate postoperatively the VAS dropped to 3.45 and after 6 month it was 2.33 and after 1 year it was 2.2 (Table 2, Fig. 4). Significant improvement of pain (defined as decrease of VAS scores of more than 50\%) was recorded immediate postoperative in eighteen patients (90\%) $(p<0.001)$. Better improvement than the postoperative baseline in later follow up was also observed.

\section{Refractures}

No further vertebral collapse was found in the injected ver-
Table 2. Comparison between the preoperative and postoperative VAS

\begin{tabular}{lccc} 
& Range & Mean & $p$-value \\
\hline VAS & & & \\
Preoperative & $3.0-10.0$ & 8.25 & \\
Immediate postoperative & $1.0-9.0$ & 3.45 & $<0.001^{*}$ \\
After 6 months & $0.0-9.0$ & 2.33 & $<0.001^{*}$ \\
After 1 year & $0.0-9.0$ & 2.2 & $<0.001^{*}$ \\
\hline
\end{tabular}

$\overline{p \text {-value for Wilcoxon signed ranks test for comparing between preoper- }}$ ative and each other periods. *Statistically significant at $p \leq 0.05$. VAS : visual analogue scale

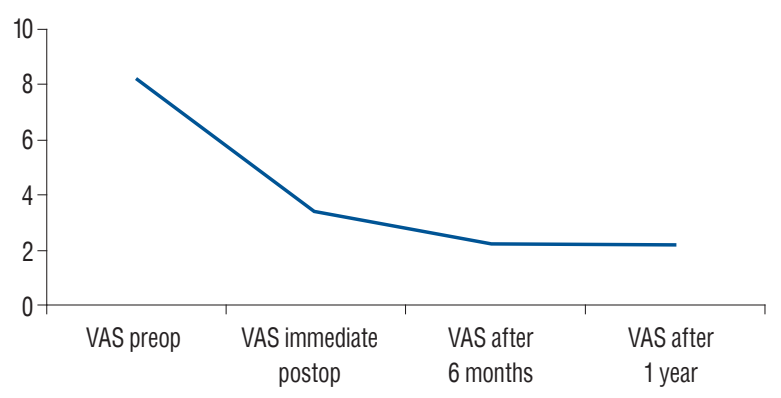

Fig. 4. A diagram showing the difference between the preoperative and postoperative VAS. VAS: visual analogue scale.

tebrae. Four out of 40 patients (10\%) developed a new fracture and required a second vertebroplasty. Two of them had fracture adjacent to vertebroplasty levels while in the other two, the fracture was distant.

\section{DISCUSSION}

PV was first performed in France and then introduced into the United States and the whole world. It was used in the management of metastatic deposits and hemangiomas. Recently, osteoporotic compression fractures are efficiently treated with $\mathrm{PV}^{5,8,13)}$. PV in osteoporotic fractures allows an effective pain reduction, early ambulation with lower complications as compared with open vertebroplasty. Also PV guards against further spinal deformity by solidifying fracture lines and restoring the bony space lost by the fracture, thus providing immediate structural support. This point can't be obtained with medical treatment ${ }^{30}$.

In the present study, we included the cases that required more than three levels injection. The minimum levels injected were four and the maximum were six. Till now, the maximum num- 
ber of vertebrae that can be injected at one session is still debatable. Barr et al. ${ }^{3)}$ have stated that single level injection is associated with better outcomes than multiple levels. Other studies suggest doing no more than three levels injection at one session to reduce the complications associated with PV as well as patient discomfort ${ }^{16)}$. Zoarski et al. ${ }^{35)}$ mentioned that up to five levels injection is acceptable and treatment of eight levels or more simultaneously is not accepted medical practice. Mailli et al. ${ }^{20)}$ found no statistical difference when comparing PV performed up to three vertebrae with more than three levels per session. This study included patients with osteoporosis, metastasis and hemangioma. They measured the degree of pain reduction and improved mobility in the follow up. They concluded that the results of PV are not dependent upon the number of vertebrae injected per session and that PV is an efficient and safe technique with multilevel injection. This was also concomitant with what was reported by Singh et al. ${ }^{25)}$ and Anselmetti et al. ${ }^{2)}$ who reached the same conclusion of performing vertebroplasty in multiple levels with safe and effective results.

Prophylactic cement injection into the vertebral body adjacent to the fractured vertebra was performed in 70 vertebrae (36\%). This technique was highly recommended by some authors to prevent new fractures after $\mathrm{PV}^{15)}$. However others ${ }^{4,12)}$ concluded that this procedure did not lower the risk of recurrence and that prediction of vertebrae at risk is difficult. The STIR sequence of MRI is very sensitive in detecting vertebral edema due to fresh fractures or micro-fractures in osteoporotic patients which is of great value to select the targeted vertebrae in multilevel PV. This will justify the risk and cost of prophylactic injection of adjacent or distant vertebrae to prevent fractures and refractures with minimal complications ${ }^{16,28)}$.

The present study showed a significant pain improvement (defined as decrease of VAS scores of more than 50\%) in $90 \%$ of the patients. Similarly, Mailli et al. ${ }^{20)}$ who studied the outcome and safety of multilevel PV found a significant pain reduction in $96.9 \%$ of their patients. The pain relief was obtained within 24 hours after the procedure and remained unchanged throughout the 2-year follow-up period. Also, Grados et al. ${ }^{10)}$ had reported a decrease of VAS from 8.0 to 3.7 after 6 months in their patients with osteoporotic fractures treated by vertebroplasty. McGraw et al. ${ }^{21)}$ reported that $97 \%$ of their patients who had undergone a PV showed a significant pain improvement after 24 hours. Similarly, other studies of PV for osteoporotic patients that used the VAS as an evaluation method showed similar results in pain improvement ${ }^{25,33,35)}$.

In the present study the overall incidence of cement_leakage was $30 \%$ however all were asymptomatic. Mailli et al. ${ }^{20)}$ showed a similar incidence (33.8\%) of cement leakage in their osteoporotic patients treated with PV. Layton et al. ${ }^{17)}$ who published a series of 1000 cases of PV in 552 patients reported a 1.8\% clinical significant complications and 25\% clinical insignificant leakages.

Leakage of bone cement into the disc space is not uncommon during vertebroplasty and usually with no clinical significance $^{19)}$. Fifteen percent of our cases showed asymptomatic cement leakage into the disc space. Increased fracture risk of adjacent vertebral bodies had been mentioned by some authors following cement leakage into the disc space however not fully documented ${ }^{19)}$. Proper needle position and cement viscosity as well as immediate cessation of injection after any leakage reduce this event.

The incidence of paravertebral cement leakage varies from $6 \%$ to $52 \%$ and is usually of no clinical significance, with very minimal incidence of peripheral neuropathy ${ }^{23)}$. In the present series the incidence of paravertebral leakage was $15 \%$ without any clinical manifestations.

Leakage of bone cement into the paravertebral veins may result in serious complications such as pulmonary or cerebral embolism, cardiac perforation, and death. High vascular vertebral pathologies, lower cement viscosity, and high injection force help leads to an increase in the intra-osseous pressure which facilitates the passage of fat and bone marrow into the venous circulation and the right heart ${ }^{6,11}$. Pulmonary cement embolism is not a common complication with vertebroplasty. It can be asymptomatic had been reported to occur in up to $4.6 \%$ of the patients ${ }^{1,11}$. Symptomatic cases present with chest pain, dyspnea and hypotension either immediate or delayed with a death risk $^{26)}$. Immediate ICU admission and medical management is required in symptomatic cases ${ }^{26}$. In the present series one patient experienced dyspnea after injection and was referred to the ICU and pulmonary embolism was diagnosed. There was no evidence of cement leakage during the injection and the patient showed a favorable recovery after treatment. Similarly, Syed et al. ${ }^{26)}$ described a similar complication following uinpedicular three levels PV in a patient who had no evidence of cement leakage and concluded that severe complications can also occur without cement leakages. Pulmonary embolism is not correlated to the number of vertebrae treated per session. This 
conclusion was reached by Benneker et al. ${ }^{4)}$ who performed a cadaveric study in 2008 and stated that reduction of the risk of cement embolization can be achieved by decreasing the force of injection as well as using a more viscous PMMA.

Pedicle fracture when passing the needle and posterior epidural leakage are also reported in the literature ${ }^{20)}$. Murphy and Deramond $^{22)}$ reported that complications associated with PV for osteoporotic fractures are less common than those in metastasis and hemangiomas. Leakage of bone cement into the epidural or foraminal space can range from asymptomatic cases to devastating motor complications up to paraplegia ${ }^{7,17)}$. Paraplegia due to neural element compression related to bone cement is rare and occurs only in $0.4 \%$ of the cases ${ }^{24)}$. Rib and transverse process fractures had also been reported to occur after $P V^{17}$. Discitis, osteomyelitis and epidural abscess can result from infection following PV and may require surgery to remove the cement which acts as nidus for infection ${ }^{34)}$.

In the literature the incidence of new vertebral fracture adjacent or distant to fractured one after vertebroplasty ranged from 7 to $37 \%^{14,27,29-31)}$. It is still unclear whether this is related to the natural history of the underlying disease or to the treatment. Lavanga et al. ${ }^{16)}$ stated the one session multilevel VP could be of help to prevent vertebral refractures even if there is not a true vertebral collapse. In the present study, we had a $10 \%$ incidence of new fractures. This was relatively consistent with what was reported by Kim et al. ${ }^{14)}$ who had a 7.9\% incidence of new fractures as well as Mailli et al. ${ }^{20)}$ who had a $7.8 \%$ incidence of new fracture in their series of 77 osteoporotic patients. Also Uppin et al. ${ }^{31)}$ reported an incidence of $12.4 \%$ of new fractures after vertebroplasty. A higher incidence of new fractures was also reported by others ${ }^{27,28,32)}$ and ranged from 21 to $37 \%$. The reason for lower incidence of refractures in the present study may be due to the multilevel injection as well as the small sample group and short term follow-up period. However, Lee et al. ${ }^{18)}$ in their analysis of risk factors causing new symptomatic vertebral compression fractures after PV for osteoporotic fractures found that aggressive bone mineral density and body mass index correction is more important than the vertebroplasty technique.

\section{CONCLUSION}

Multilevel PV for the treatment of osteoporotic fractures is a safe and successful procedure that can significantly reduce pain and improve patient's condition without a significant morbidity. PV allows treatment of the already fractured vertebrae and reduces the incidence of refractures in osteoporosis. It is considered a cost effective procedure allowing a rapid restoration of patient mobility.

\section{CONFLICTS OF INTEREST}

No potential conflict of interest relevant to this article was reported.

\section{INFORMED CONSENT}

Informed consent was obtained from all individual participants included in this study.

\section{References}

1. Aebli N, Krebs J, Davis G, Walton M, Williams MJ, Theis JC : Fat embolism and acute hypotension during vertebroplasty: an experimental study in sheep. Spine (Phila Pa 1976) 27 : 460-466, 2002

2. Anselmetti GC, Corrao G, Monica PD, Tartaglia V, Manca A, Eminefendic $H$, et al. : Pain relief following percutaneous vertebroplasty: results of a series of 283 consecutive patients treated in a single institution. Cardiovasc Intervent Radiol 30 : 441-447, 2007

3. Barr JD, Barr MS, Lemley TJ, McCann RM : Percutaneous vertebroplasty for pain relief and spinal stabilization. Spine (Phila Pa 1976) 25 : 923928, 2000

4. Benneker LM, Heini PF, Suhm N, Gisep A : The effect of pulsed jet lavage in vertebroplasty on injection forces of polymethylmethacrylate bone cement, material distribution, and potential fat embolism: a cadaver study. Spine (Phila Pa 1976) 33 : E906-E910, 2008

5. Braunstein V, Sprecher CM, Gisep A, Benneker L, Yen K, Schneider E, et al. : Long-term reaction to bone cement in osteoporotic bone: new bone formation in vertebral bodies after vertebroplasty. J Anat 212 : 697-701, 2008

6. Chen HL, Wong CS, Ho ST, Chang FL, Hsu CH, Wu CT : A lethal pulmonary embolism during percutaneous vertebroplasty. Anesth Analg 95 : 1060-1062, 2002

7. Chiras J, Depriester C, Weill A, Sola-Martinez MT, Deramond H : Percutaneous vertebral surgery. Technics and indication. J Neuroradiol 24 : 45-59, 1997

8. Cyteval C, Thomas E, Solignac D, Blin D, Decoux E, Lopez F, et al. : Pro- 
spective evaluation of fracture risk in osteoporotic patients after low cement volume vertebroplasty. J Radiol 89 : 797-801, 2008

9. Evans $A J$, Jensen $M E, K i p K E$, DeNardo AJ, Lawler GJ, Negin GA, et al. : Vertebral compression fractures: pain reduction and improvement in functional mobility after percutaneous polymethylmethacrylate vertebroplasty retrospective report of 245 cases. Radiology 226 : 366-372, 2003

10. Grados F, Depriester C, Cayrolle G, Hardy N, Deramond H, Fardellone P : Long-term observations of vertebral osteoporotic fractures treated by percutaneous vertebroplasty. Rheumatology (Oxford) 39 : 14101414,2000

11. Jang JS, Lee SH, Jung SK : Pulmonary embolism of polymethylmethacrylate after percutaneous vertebroplasty: a report of three cases. Spine (Phila Pa 1976) 27 : E416-E418, 2002

12. Kallmes DF, Jensen ME : Percutaneous vertebroplasty. Radiology 229 : 27-36, 2003

13. Kim AK, Jensen ME, Dion JE, Schweickert PA, Kaufmann TJ, Kallmes DF : Unilateral transpedicular percutaneous vertebroplasty: initial experience. Radiology 222 : 737-741, 2002

14. Kim SH, Kang HS, Choi JA, Ahn JM : Risk factors of new compression fractures in adjacent vertebrae after percutaneous vertebroplasty. Acta Radiol 45 : 440-445, 2004

15. Kobayashi N, Numaguchi Y, Fuwa S, Uemura A, Matsusako M, Okajima Y, et al. : Prophylactic vertebroplasty: cement injection into non-fractured vertebral bodies during percutaneous vertebroplasty. Acad Radiol 16 : 136-143, 2009

16. Lavanga A, Guarnieri G, Muto M : Medical therapy and multilevel vertebroplasty in osteoporosis: when and why. Neuroradiol J 23 : 244-248, 2010

17. Layton KF, Thielen KR, Koch CA, Luetmer PH, Lane JI, Wald JT, et al. : Vertebroplasty, first 1000 levels of a single center: evaluation of the outcomes and complications. AJNR Am J Neuroradiol 28 : 683-689, 2007

18. Lee DG, Park CK, Park CJ, Lee DC, Hwang JH : Analysis of risk factors causing new symptomatic vertebral compression fractures after percutaneous vertebroplasty for painful osteoporotic vertebral compression fractures: a 4-year follow-up. J Spinal Disord Tech 28 : E578-E583, 2015

19. Lin EP, Ekholm S, Hiwatashi A, Westesson PL : Vertebroplasty: cement leakage into the disc increases the risk of new fracture of adjacent vertebral body. AJNR Am J Neuroradiol 25 : 175-180, 2004

20. Mailli L, Filippiadis DK, Brountzos EN, Alexopoulou E, Kelekis N, Kelekis A : Clinical outcome and safety of multilevel vertebroplasty: clinical experience and results. Cardiovasc Intervent Radiol 36 : 183-191, 2013

21. McGraw JK, Lippert JA, Minkus KD, Rami PM, Davis TM, Budzik RF : Prospective evaluation of pain relief in 100 patients undergoing percutaneous vertebroplasty: results and follow-up. J Vasc Interv Radiol 13(9 Pt 1) : 883-886, 2002
22. Murphy KJ, Deramond $\mathrm{H}$ : Percutaneous vertebroplasty in benign and malignant disease. Neuroimaging Clin N Am 10 : 535-545, 2000

23. Peh WC, Gilula LA, Peck DD : Percutaneous vertebroplasty for severe osteoporotic vertebral body compression fractures. Radiology 223 : 121126, 2002

24. Ryu KS, Park CK, Kim MC, Kang JK : Dose-dependent epidural leakage of polymethylmethacrylate after percutaneous vertebroplasty in patients with osteoporotic vertebral compression fractures. J Neurosurg 96(1 Suppl) : 56-61, 2002

25. Singh AK, Pilgram TK, Gilula LA : Osteoporotic compression fractures: outcomes after single-versus multiple-level percutaneous vertebroplasty. Radiology 238 : 211-220, 2006

26. Syed MI, Jan S, Patel NA, Shaikh A, Marsh RA, Stewart RV : Fatal fat embolism after vertebroplasty: identification of the high-risk patient. AJNR Am J Neuroradiol 27 : 343-345, 2006

27. Syed MI, Patel NA, Jan S, Harron MS, Morar K, Shaikh A : New symptomatic vertebral compression fractures within a year following vertebroplasty in osteoporotic women. AJNR Am J Neuroradiol 26 : 16011604,2005

28. Spiegl UJ, Beisse R, Hauck S, Grillhösl A, Bühren V : Value of MRI imaging prior to a kyphoplasty for osteoporotic insufficiency fractures. Eur Spine J 18 : 1287-1292, 2009

29. Tanigawa N, Komemushi A, Kariya S, Kojima H, Shomura Y, Sawada S : Radiological follow-up of new compression fractures following percutaneous vertebroplasty. Cardiovasc Intervent Radiol 29 : 92-96, 2006

30. Tsou IY, Goh PY, Peh WC, Goh LA, Chee TS : Percutaneous vertebroplasty in the management of osteoporotic vertebral compression fractures: initial experience. Ann Acad Med Singapore 31 : 15-20, 2002

31. Uppin AA, Hirsch JA, Centenera LV, Pfiefer BA, Pazianos AG, Choi IS: Occurrence of new vertebral body fracture after percutaneous vertebroplasty in patients with osteoporosis. Radiology 226 : 119-124, 2003

32. Voormolen MH, Lohle PN, Juttmann JR, van der Graaf $Y$, Fransen $H$, Lampmann LE : The risk of new osteoporotic vertebral compression fractures in the year after percutaneous vertebroplasty. J Vasc Interv Radiol 17 : 71-76, 2006

33. Voormolen $M H$, Lohle PN, Lampmann LE, van den Wildenberg $W$, Juttmann JR, Diekerhof $\mathrm{CH}$, et al. : Prospective clinical follow-up after percutaneous vertebroplasty in patients with painful osteoporotic vertebral compression fractures. J Vasc Interv Radiol 17 : 1313-1320, 2006

34. Yu SW, Chen WJ, Lin WC, Chen YJ, Tu YK : Serious pyogenic spondylitis following vertebroplasty--a case report. Spine (Phila Pa 1976) 29 : E209-E211, 2004

35. Zoarski GH, Snow P, Olan WJ, Stallmeyer MJ, Dick BW, Hebel JR, et al. : Percutaneous vertebroplasty for osteoporotic compression fractures: quantitative prospective evaluation of long-term outcomes. J Vasc Interv Radiol 13(2 Pt 1) : 139-148, 2002 